\title{
Numerical Seismic Assessment of Masonry Made of Compressed Earth Blocks
}

\author{
Riccardo Nitiffi, Maura Imbimbo \\ University of Cassino and Southern Lazio, Italy
}

\section{Ernesto Grande}

University Guglielmo Marconi, Italy

\author{
Daniel V. Oliveira \\ University of Minho, Guimarães, Portugal
}

Contact: danvco@civil.uminho.pt

\begin{abstract}
Masonry construction built with compressed earth blocks (CEBs) is one of the most significant examples of sustainable buildings based on the earth construction technology. Nevertheless, despite the economic and environmental advantages, the seismic vulnerability of these construction is object of concern. The aim of the present paper is to numerically investigate the response of a one-story CEB masonry building subjected to horizontal forces simulating seismic actions. Both modal and non-linear static analyses are performed through the commercial Finite Element (FE) code TNO-DIANA by using a 3D FE macro-modelling approach. During the analyses, particular attention has been devoted to the influence of some structural elements such as interior partition walls and ring beams.
\end{abstract}

Keywords: earthen structures; compressed earth blocks; FE macro-modelling; modal analysis; pushover analysis.

\section{Introduction}

A large amount of current literature in the field of civil engineering is focused on the sustainability of construction. Studies specifically concerning buildings made of local materials, which are generally characterized by good levels of environmental and economical sustainability, have been carried out with the main goal of investigating solutions able to guarantee adequate structural performance levels, particularly in case of seismic events. In this context, masonry construction built with compressed earth blocks (CEBs) is one of the examples of improving the traditional earth construction technology. Indeed, the soil used for CEBs can be first stabilized with a low amount of cement and/or lime and, then, mechanically compressed in a rigid mould, reaching a high compaction level. The soil blocks obtained from this process are cured and then air dried. This production process creates blocks with regular shapes and sizes, with high strength and 
durability properties and without the use of fuel. Despite the proven advantages of this material, the seismic vulnerability of buildings made of CEBs is still one of the major concerns in the field of earthen construction. In fact, the seismic performance of earthen construction is generally poor in comparison with contemporary structures, due to the materials low strength and the absence of structural details, which play an important role in the seismic response. For these reasons, it is urgent to adopt conservation measures, which may also include strengthening solutions for improving the in-plane and out-of-plane behaviour of the walls.

The aim of the present paper is to numerically investigate the response of a one-story CEB masonry building subjected to horizontal forces simulating seismic actions. For this aim, both modal and non-linear static analyses are performed through the commercial FE code TNODIANA [1] by using a 3D FE macro-modelling approach. During the analyses, particular attention has been devoted to the influence of some structural elements such as interior partition walls and ring beams.

\section{Compressed earth block masonry}

Some recent experimental work on CEBs are available in literature. They mainly concern the mechanical characterization of units and masonry components. Among these, Sturm et al. [2] presented an experimental campaign on dry-stack masonry with stabilized interlocking compressed earth blocks (ICEBs) used as a low-cost and ecoefficient material for housing in developing countries. In particular, the campaign was aimed at characterizing the dry-stack masonry at three different levels: the mechanical characterization of stabilized soil-cement mix, the strength of the ICEB blocks and the compressive strength of the masonry prisms and wallets with dry interface.

The study developed by Silva et al. [3] analysed the mechanical characterization of dry-stack masonry made of CEBs stabilized with alkaline activation of fly ash. The obtained results show an excellent improvement of the mechanical performance of the masonry with respect to the CEBs manufactured with traditional chemical stabilization. More recently, Oliveira et al. [4] conducted an experimental campaign on compressed earth block masonry, produced with granitic residual soils, addition of kaolin and cement stabilization. The prism and wallet specimens were characterized by two different joint configurations, namely dry-stack and mortared, in order to investigate the influence of connections on its mechanical response. The results show that the use of mortared joints modifies significantly the mechanical behaviour of masonry, both in terms of stiffness and strength. Like for the prisms, the results on wallets also underline a better performance of mortared joint masonry with respect to dry-stack ones. In fact, the mortared wallets generally show higher strength, higher stiffness and lower deformation, in the axial and transversal directions, than those of dry-stack wallets, confirming the advantage, in terms of mechanical behaviour, of using mortared joints instead of dry-stack masonry, especially in high prone seismic zones.

\section{Case study: HiLoTech house}

The case study here analysed is the one-story building shown in Figure 1. This case, denoted in the following as HLT house, is a prototype building developed in the context of the HiLoTech Project [5] for housing in rural areas of developing countries, with particular regard to Malawi.

The external walls and the internal partitions of the HLT house are made of double and single-leaf CEB walls, respectively. Indeed, the thickness of external walls, equal to $28 \mathrm{~cm}$, is twice the thickness of the internal partitions. These dimensions are in agreement with the recommendations of the NZS 4299 [6] for CEB walls. A further structural element characterizing the HLT house is a ring beam provided at the top of both external and internal walls (Figure 1). The ring beam is made of a low strength concrete (compressive strength of $12 \mathrm{MPa}$ ) and it is characterized by a $150 \times 140 \mathrm{~mm}^{2}$ cross-section dimensions, with a steel reinforcement composed of four $8 \mathrm{~mm}$-diameter bars, for the ring beam over the internal walls, and $150 \times 280 \mathrm{~mm}^{2}$ cross-section dimensions, with a steel reinforcement composed of four $10 \mathrm{~mm}$-diameter bars plus two $8 \mathrm{~mm}$-diameter bars, for the ring beam over the external walls. 

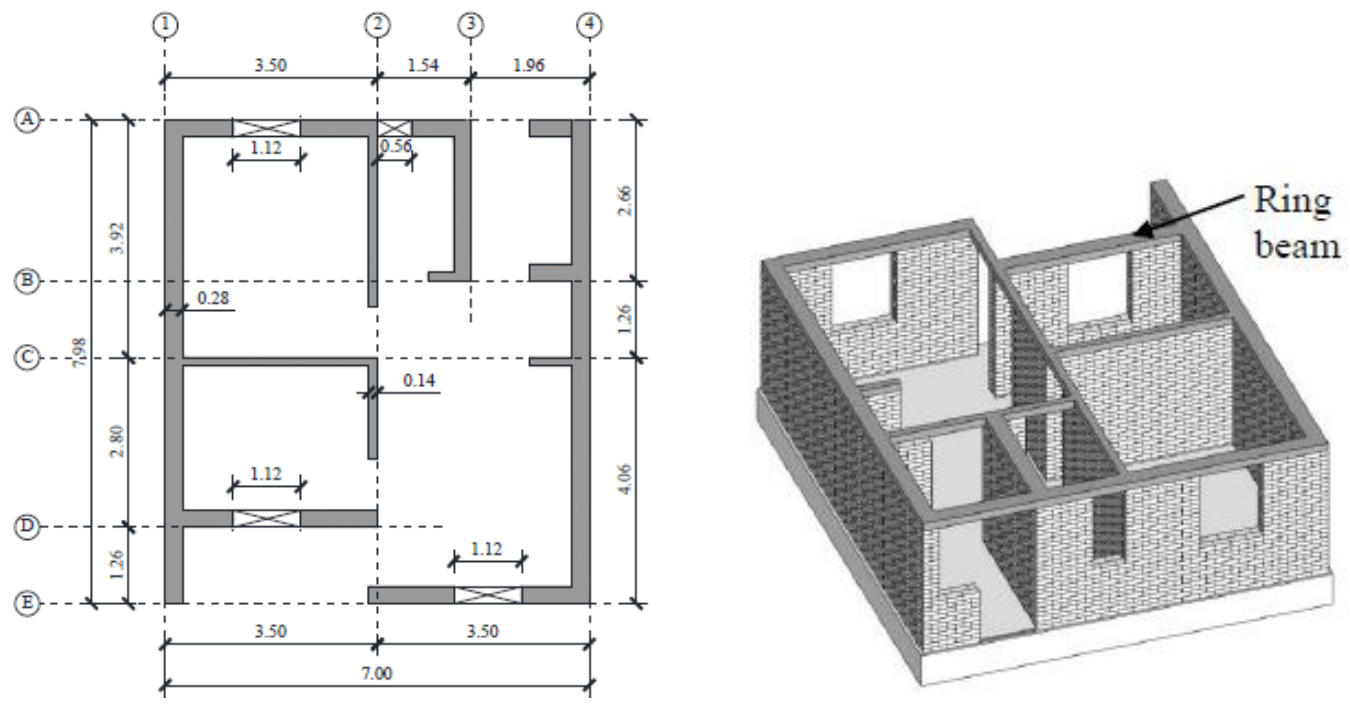

Figure 1. Plan and axonometric view of the HLT house [7]

\section{FE modelling approach}

The numerical analyses presented in this paper are based on a 3D FE macro-modelling approach and they are carried out by using the commercial computer code TNO-DIANA [1]. Since the aim of the analysis is to numerically investigate the seismic response of the HLT house by accounting for the role of the interior partition walls and a reinforced concrete ring beam located on the top of external and interior partition walls, the following three FE models of the HLT house have been considered:

- model 1: the HLT house with the external walls only (Figure 2.a)

- model 2: the HLT house with the presence of both the external and the interior partition walls (Figure 2.b);

- model 3: the HLT house characterized by the presence of the external walls, the interior partition walls and the ring beam (Figure 2.c).

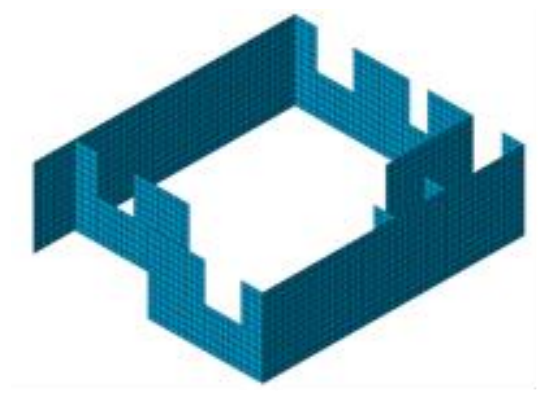

a)

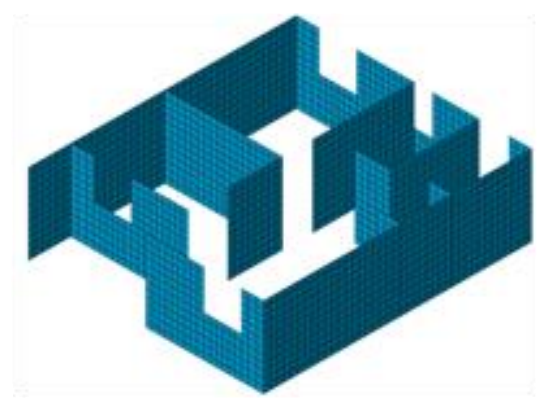

b)

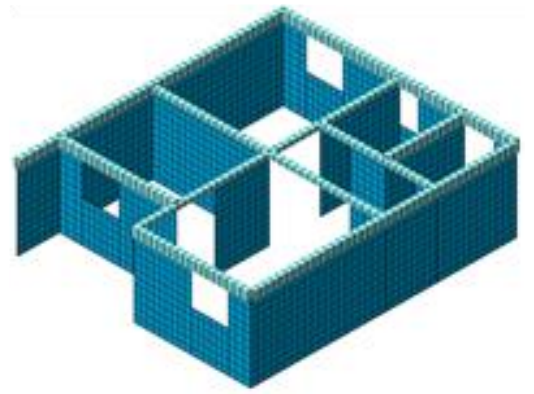

c)

Figure 2. 3D FE models accounted for the numerical analyses: a) model 1; b) model 2; c) model 3.

In order to reduce the computational effort while preserving a good level of reliability of results, eight-node quadrilateral isoparametric curved shell elements, based on quadratic interpolation and Gauss integration over the element area, have been used for modelling both the external partition walls and the interior partitions. On the other hand, a beam-element type has been selected for modelling the ring beam in the case of model 3. In particular, a perfect adhesion between the ring beam element and the walls has been assumed. 
A further important step concerns the modelling of the CEB material composing the walls of the HLT house. In particular, considering the results of the experimental tests available in current literature [2] [4], showing a brittle behaviour of CEB material with tensile strength values significantly lower than the compressive ones, constitutive laws characterized by a post-peak softening branch have been here selected for modelling the behaviour in tension and compression of the CEB material (Figure 3) where $h$ is the crack bandwidth. The parameters characterizing these laws, deduced from literature [4], are summarized in Table 1.

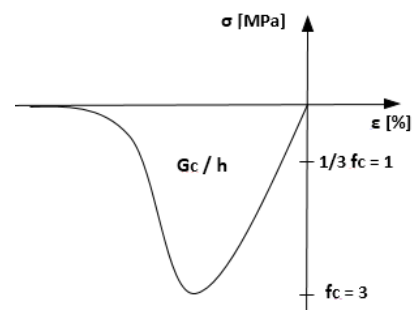

a)

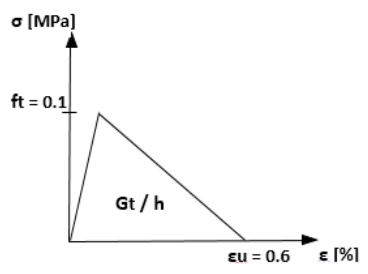

b)
Figure 3. Constitutive laws selected for the CEB material: a) compression; b) tension

Table 1. Parameters characterizing the CEB material

\begin{tabular}{llll}
\hline $\boldsymbol{v}$ & Poisson's ratio & 0.15 & \\
\hline $\boldsymbol{E}$ & Young's modulus & 500 & $\mathrm{MPa}$ \\
\hline $\boldsymbol{v}$ & Mass density & 1950 & $\mathrm{Kg} / \mathrm{m}^{3}$ \\
\hline $\boldsymbol{f}_{\mathrm{c}}$ & Compressive strength & 3 & $\mathrm{MPa}$ \\
\hline $\boldsymbol{G}_{\mathrm{c}}$ & Compressive fracture energy & 2 & $\mathrm{~N} / \mathrm{mm}$ \\
\hline $\boldsymbol{f}_{\mathrm{t}}$ & Tensile strength & 0.1 & $\mathrm{MPa}$ \\
\hline $\boldsymbol{G}_{\mathrm{t}}$ & Tensile fracture energy & 0.05 & $\mathrm{~N} / \mathrm{mm}$ \\
\hline
\end{tabular}

In addition to the constitutive laws selected for the CEB material, a smeared crack approach has been introduced in the FE-model in order to account for the influence of material damage on the global response of the 3D model. This approach has the advantage of representing the cracks throughout changes of the constitutive equations (smeared models) instead of changes on the finite element mesh (discrete models). In particular, the Total Strain Rotating Crack model option has been selected in DIANA [1] since it allows the change of the crack orientation by following the principal directions. Finally, a linear elastic behaviour has been adopted for the concrete material composing the ring beam (Table 2).

Table 2. Parameters characterizing the ring beam

\begin{tabular}{llll}
\hline $\boldsymbol{v}$ & Poisson's ratio & 0.2 & \\
\hline $\boldsymbol{E}$ & Young's modulus & 29000 & $\mathrm{MPa}$ \\
\hline $\boldsymbol{v}$ & Mass density & 2500 & $\mathrm{Kg} / \mathrm{m}^{3}$ \\
\hline
\end{tabular}

\section{Numerical analyses}

In addition to pushover analyses, which are specifically devoted to derive information on the non-linear response of the HLT house, modal analyses have been also developed in order to evaluate the dynamic properties of the three analysed models. The outcomes emerged from both types of analysis are reported in the following paragraphs.

\subsection{Modal analysis}

One of the main features of the HLT house is the presence of a light wooden roof simply placed on the top of the perimeter walls. This structural part only leads to a small increase of the mass of the building system without significantly interacting with walls and thus affecting the building strength. Indeed, as shown in the following, different from buildings where rigid floors connecting the walls and lead to a global dynamic box-behaviour, the dynamic response of the HLT house is mainly characterized by the local vibration modes of walls. This behaviour has been confirmed by the effective modal mass ratios obtained from the performed modal analyses (see Figures 4, 5, and 6).

Indeed, it has been observed that the introduction of the internal partition walls leads to an increase of the period corresponding to the first mode of vibration and to a variation of the modal shape. In fact, the first mode of vibration of model 1 mainly develops along $y$-direction with a period of $0,22 \mathrm{~s}$, whilst the first mode of model 2 mainly develops along $\mathrm{x}$-direction with a period of $0,31 \mathrm{~s}$. Although 
the introduction of the internal partition walls contributes to increase the lateral stiffness of the building, it also leads to an increase of the mass. Moreover, considering the configuration of the building, the internal walls are not connected and they are irregularly distributed in plan. This aspect does not provide a significant increase of the lateral global stiffness of the building, but it does aggravate the level of the plan irregularity.

In both models, low values of the modal participating mass ratio characterize the majority of the modes. The introduction of the ring beam, which connects the external and the internal walls, leads to a significant reduction of the period corresponding to the first modes of vibration. In addition, an increase of the modal participating mass ratios of the first modes can be observed.

In spite of the presence of the ring beam, also model 3 underlines an irregular in-plan dynamic behaviour as showed by the first mode of vibration, which results torsional.

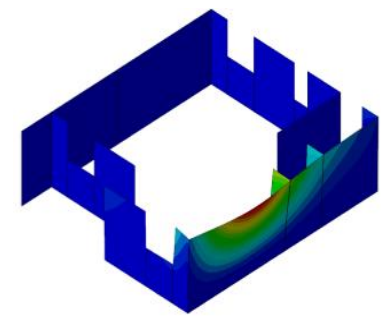

a)

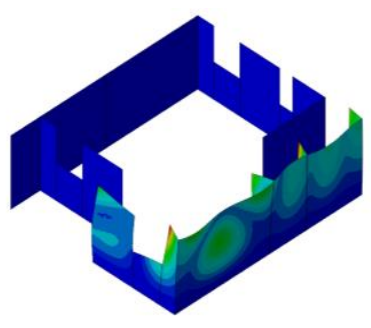

b)
Figure 4. Modal deformed shapes of the modes with the highest values of modal participating mass ratios (model 1): a) mode $6, M x=13,8 \%$; b) mode $32, M y=9,2 \%$.

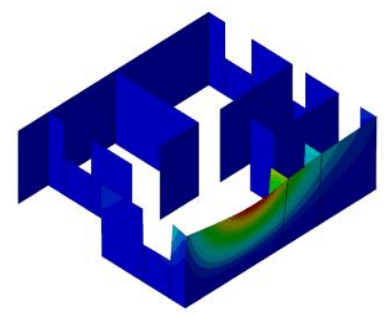

a)

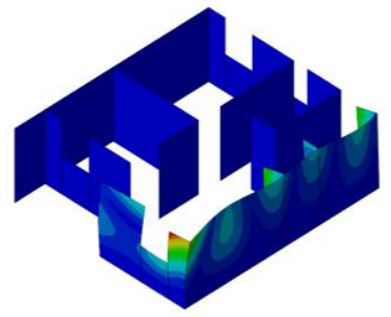

b)
Figure 5. Modal deformed shapes of the modes with the highest values of modal participating mass ratios (model 2): a) mode 5, $M x=12,0 \%$; b) mode $28, M y=4,6 \%$.

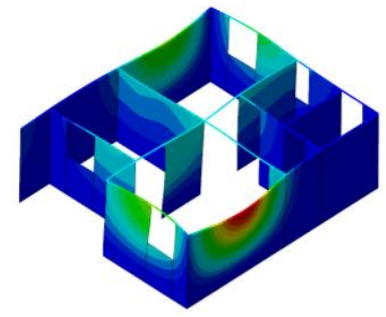

a)

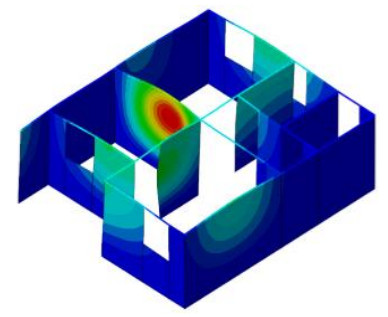

b)
Figure 6. Modal deformed shapes of the modes with the highest values of modal participating mass ratios (model 3): a) mode $1, M x=16,6 \%$; b) mode $3, M y=21,9 \%$.

\subsection{Pushover analysis}

Nonlinear static analyses (pushover) are performed by applying monotonically increasing horizontal forces to the entire model. The horizontal forces, proportional to the mass of the finite element model, act along the principal plan axes in both the positive and the negative directions. The results are reported in terms of deformed shape and capacity curve for all the three models previously mentioned.

The derivation of the capacity curve from pushover analyses, i.e. a curve in terms of base shear vs. displacement, representative of the global response of the system, necessarily requires the selection of a proper control point. In particular, while in case of buildings with rigid floors this choice is made by selecting an arbitrary point of the roof (the capacity curve is not substantially affected by the position of the point), here the selection of the point at the roof particularly influences the capacity curve both in the pre and post peak phase. In this case, many authors suggest selecting the point at the top of wall that exhibits the maximum value of the displacement [8]. In the present study, for both models 1 and 2, the reported capacity curves have been obtained by considering as control point the one corresponding to the maximum displacement exhibited by walls along the two principal directions (see also Figure 7 and Figure 8).

Different, for the model 3 , the control point corresponds to the intersection of the internal ring beams, because of the lower influence of local modes on the dynamic response of the building (Figure 9). 

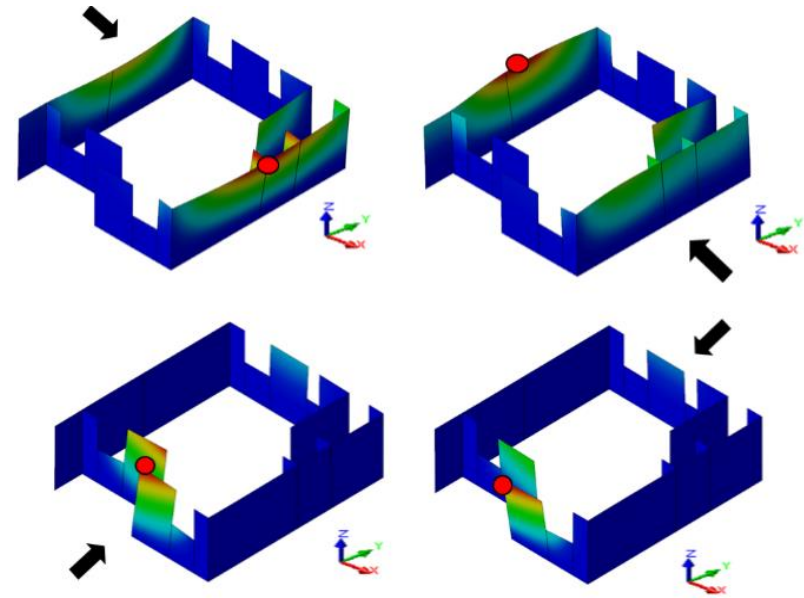

Figure 7. Selected control points for the derivation of capacity curves from pushover analyses: model 1.
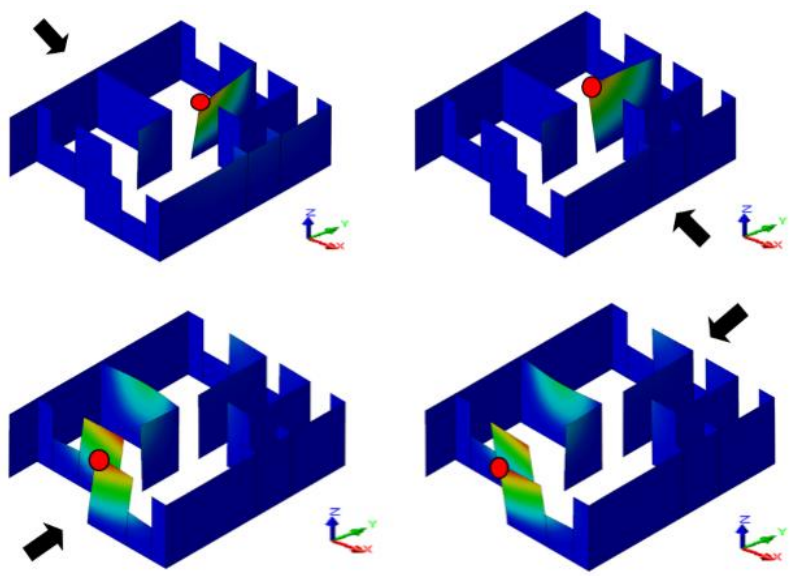

Figure 8. Selected control points for the derivation of capacity curves from pushover analyses: model 2.
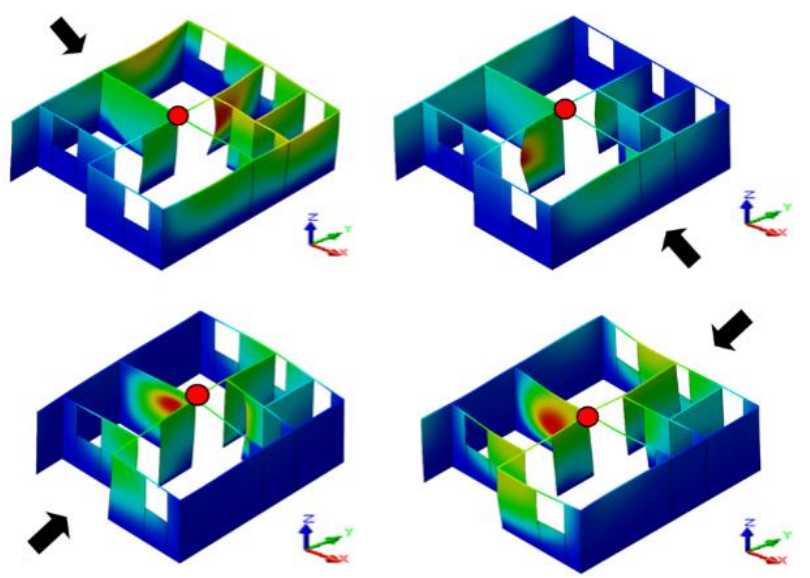

Figure 9. Selected control points for the derivation of capacity curves from pushover analyses: model 3.

The capacity curves are reported in Figure 10 to Figure 12 in terms of the load factor $\alpha$ (ratio between the base shear force and the weight of the building) vs. the drift (ratio between the displacement of the control point $D$ and the height of the structure $H$ ).

Considering the pushover analysis of model 1 developed by applying horizontal forces acting along $+X$ direction (Figure 10), the obtained maximum load factor is equal to 0,29 . In case of forces applied along -X direction (Figure 10), the capacity curve shows a trend similar to the one obtained by applying the horizontal forces along $+X$. Nevertheless, a greater value of the maximum load factor is obtained $(0,33)$. These curves show a similar shape and, at the same time, they remark a ductile post-peak behaviour. Since the nonlinear behaviour is mainly governed by an exterior wall, free along one vertical side, the control points along the two pushover directions are coincident. By examining the deformed shape of walls at the different steps of the pushover, it emerges a considerable out-of-plane mechanism of some of the walls.

The capacity curves derived for the model 2 are shown in Figure 11. Both curves show a ductile post peak behaviour. In particular, in case of $+X$ direction, the maximum displacement is attained at the top of an internal partition. The same partition, and then the same control point, characterizes the response along $-X$ direction. The capacity curves corresponding to $+Y$ and $-Y$ directions are similar to the corresponding curves of the model 1: this depends on the fact that the wall characterized by the maximum displacement is the same of model 1 , and then also the control point is the same (see Figure 7and Figure 8 ).

Finally, the capacity curves for the model 3 are shown in Figure 12 . These curves exhibit a behaviour quite different from the one characterizing model 1 and model 2. In particular, a significant increase of the peak load (strength capacity) is evident due to the interaction among the exterior and interior walls, thanks to the presence of the ring beam. On the other hand, both capacity curves of model 3 underline a fragile post-peak behaviour due to the change of the predominant failure mechanism. Indeed, the deformed shape renders evident that the ring beam contrasts the out-of-plane cantilever behaviour of walls emerged on the contrary for model 1 and model 2 . 

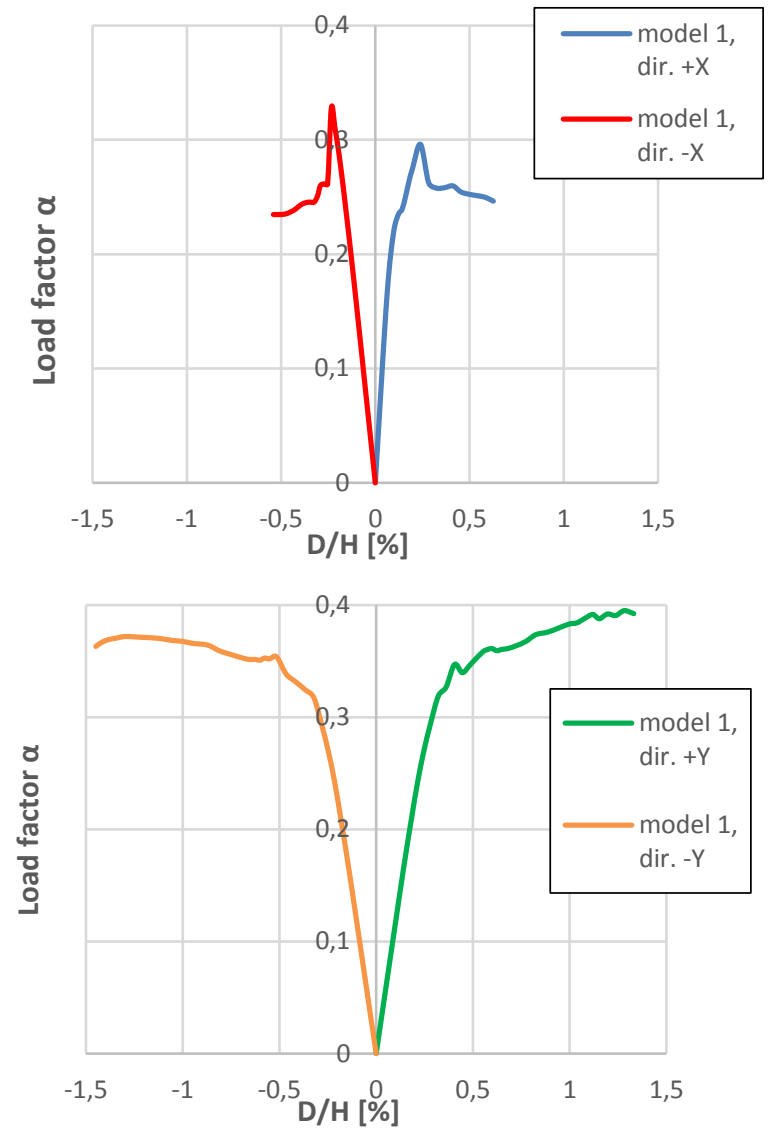

Figure 10. Capacity curves (model 1).
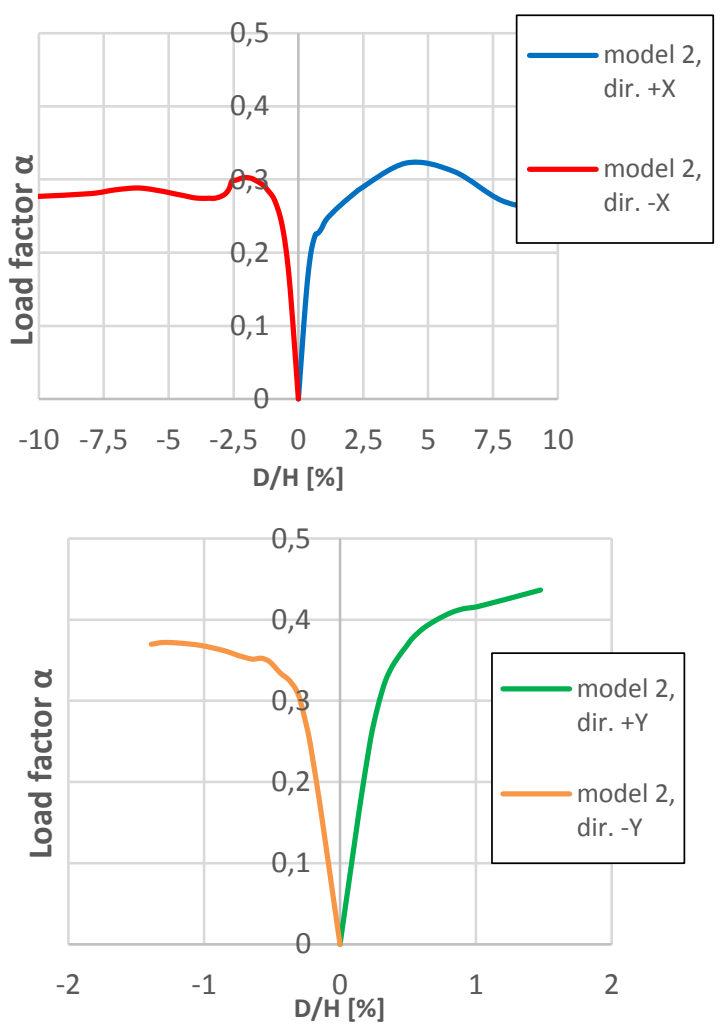

Figure 11. Capacity curves (model 2).
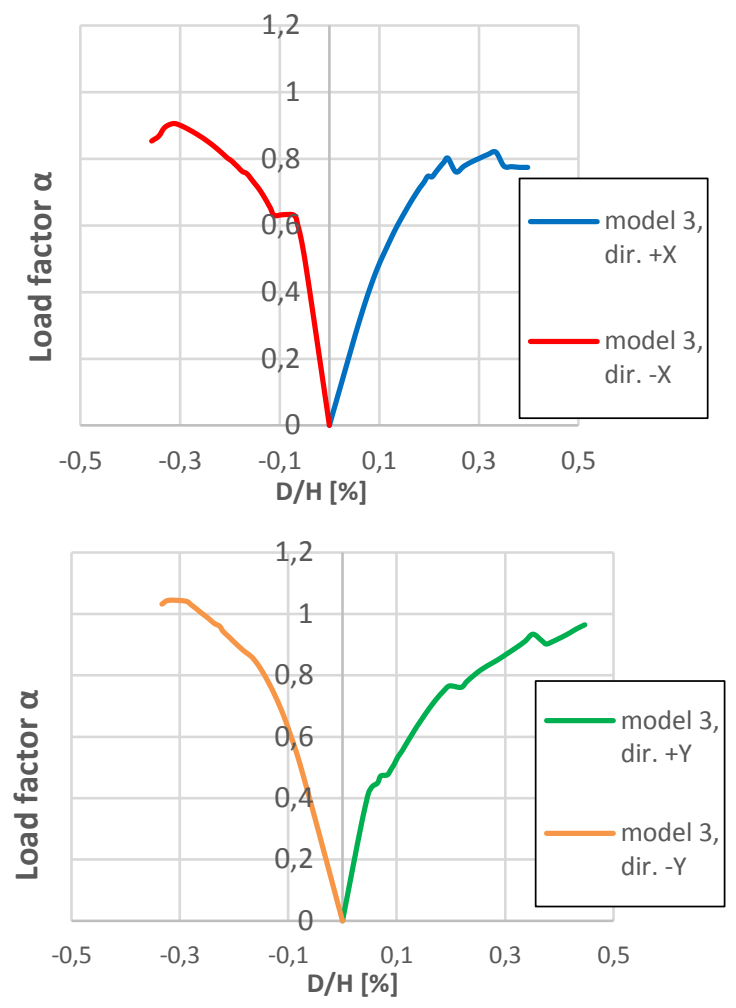

Figure 12. Capacity curves (model 3).

\subsection{Remarks and considerations}

The results emerged from the numerical analyses have underlined important aspects concerning the seismic response of the HLT house and the influence of the interior partition walls and the ring beam as additional possible structural components.

As expected, the modal analyses have emphasized the predominance of local vibration modes of walls in case of both models 1 and 2. On the other hand, the presence of the ring beam (model 3) improves the interaction among the walls leading to global vibration modes characterized by higher values of the participating mass ratio and significant reductions of the periods of vibration.

The pushover analyses have emphasized additional features depending on both the characteristics emerged from the modal analyses and on the nonlinear behaviour at the material level. While the presence of partition walls (model 2) does not significantly affects the peak load (strength), the presence of the ring beam (model 3) leads to a substantially increasing of the peak 
load. On the other hand, a remarkable fragile behaviour has emerged in case of model 3 .

Although the trend of capacity curves is dependent on the selection of the control point (particularly for model 1 and model 2), the different post-peak behaviour showed by the model 3 is mainly affected by the change of the behaviour of walls within the resistant mechanism of building. While in case of model 1 and model 2 the walls behave as cantilevers with damage patterns mainly due to the out-of-plane mechanism, in case of model 3, the ring beam opposes to this mechanism thanks to the cooperation among the walls, which mainly contribute to the global resistant mechanism in terms of an in-plane mechanism.

\section{Conclusions}

This paper presents a numerical investigation concerning the nonlinear behaviour of a CEB house to horizontal forces simulating seismic actions. Particular attention has been devoted to the influence of additional structural components such as the interior partition walls and a reinforced concrete ring beam located along the upper side of walls.

With reference to the HLT house prototype, characterized by a light wooden roof placed on the exterior walls and a low strength material composing the walls, the numerical results have evidenced a significant improvement of the global seismic response thanks to the introduction of a ring beam. Indeed, this structural detail, widely employed in the seismic rehabilitation of classical masonry constructions, allows to improve the level of interaction among the partition walls leading to a global resistant mechanism of the building instead of the predominance of local modes and then, damage concentrations in few elements.

In the case of the HLT house, the execution of the rig beam can be simply added to the construction without any significant efforts since it is simply placed on the top of the walls before introducing the roof structure.

\section{References}

[1] TNO-DIANA, User's Manual, Release 9.6, Delft, The Netherlands. 2015.

[2] Sturm T., Ramos L. F., Lourenço P.B. Characterization of dry-stack interlocking compressed earth blocks. Materials and structures; 2015; 48: 3059-3074.

[3] Silva R.A., Soares E., Oliveira D.V., Miranda T., Cristelo N., Leitão D. Mechanical characterization of dry-stack masonry made of CEBs stabilized with alkaline activation. Construction and Building materials. 2015; Vol. 75.

[4] Oliveira D.V., Miranda T.F., Ramos L.F., Silva R.A., Soares E., Leitão D. Mechanical performance of compressed earth block masonry using granitic residual soils. 16th international brick and block masonry conference. 2016 June 26-30; Padova, Italy.

[5] Ramos L.F., Sturm T., Gomes D., Mendonça P., Eires R., Camões A., Lourenço P.B. Hilotec - Self-building manual for sustainable housing. University of Minho, School of Civil Engineering, ISBN: 978-9728692-88-9; 2014.

[6] NZS4299. Earth buildings not requiring specific design. Standards New Zealand, Wellington; 1998.

[7] Sturm T. Experimental characterization of dry-stack interlocking compressed earth block masonry, PhD Thesis, University of Minho, 2014.

[8] Cattari S., Camilletti D., Marino S., Lagomarsino S. Valutazione della risposta sismica di edifici in muratura irregolari in pianta e con solai flessibili. XVI conv. ANIDIS; 2015 Sep 13-17; L'Aquila, Italy. (In Italian). 